\title{
Domestic versus International Portfolio Selection: A Statistical Examination of the Home Bias
}

\author{
Larry R. Gorman \\ California Polytechnic State University, U.S.A. \\ Bjorn N. Jorgensen \\ Columbia University, U.S.A.
}

\begin{abstract}
The observed international home bias has traditionally been viewed as an anomaly. This paper provides statistical evidence contrary to this view within a mean-variance framework. Two methods of estimating the expected return and covariance parameters are investigated: (i) the traditional Markowitz approach, and (ii) the Bayes-Stein "shrinkage" algorithm. In-sample tests reveal that neither the Markowitz tangency allocation vectors nor the Bayes-Stein tangency allocation vectors are significantly different than a 100\% domestic allocation (i.e. extreme home bias). These results are robust to the shorting of equity and across foreign exchange hedge strategies. The paper also reports out-of-sample tests with a view toward investment performance. Typically, a $100 \%$ domestic allocation outperforms both the Bayes-Stein and Markowitz tangency portfolios. Overall, the theorized gains to international diversification appear difficult to capture in practice and, hence, investors exhibiting a strong home bias are not necessarily acting irrationally (JEL F3, G11, G12, G15).
\end{abstract}

Keywords: efficient allocation, foreign exchange hedging, home bias, international allocation, portfolio.

${ }^{*}$ We wish to thank Torben Andersen, Phillip Braun, Ian Domowitz, Thomas Fields, John Heaton, Robert Hodrick, Ken Kavajecz, Robert Korajczyk, Nick Polson, Robert Simon, Casper de Vries, three anonymous referees, and seminar participants at Arizona, Cal Poly, DePaul, Emory, Georgia, Harvard, Marquette, Northwestern, Texas A\&M, Tinbergen Institute of Rotterdam, and Washington State University for helpful comments. All errors remain ours.

(Multinational Finance Journal, 2002, vol. 6, no. 3\&4, pp. 131-166)

(CMultinational Finance Society, a nonprofit corporation. All rights reserved.

DOI: $10.17578 / 6-3 / 4-1$ 


\section{Introduction}

The international CAPM predicts that investors in different countries should invest in portfolios whose risk and return characteristics are similar. ${ }^{1}$ In reality, shareholders in each country allocate substantially more to domestic assets than to foreign assets. For example, French and Poterba (1991) note that "domestic ownership shares of the world's five largest stock markets are: United States, 92.9\%; Japan, 95.7\%; United Kingdom, 92\%; Germany, 79\%; and France, 89.4\%." The common label for this phenomenon, "home bias", suggests that investors' preference for domestic equity is irrational, see Lewis (1999). This paper uses statistical tests to demonstrate that observing a home bias does not necessarily imply that investors are irrational.

The original literature on international portfolio choice establishes that investors should benefit from international diversification through a shift in the efficient frontier, see Solnik (1974) and Levy (1980), among others. Recently, De Santis (1995), Bekaert and Urias (1996), De Santis and Gerard (1997) conclude that shifts in the efficient frontier are not statistically significant. These results are robust to the inclusion of emerging markets, see Errunza, Hogan, and Hung (1999). In a similar spirit, this paper concludes that observed portfolio allocation weights are not significantly different than an optimal allocation. The implication is that extreme home bias allocations are insignificantly different than optimal allocations, and therefore domestically oriented investors are not necessarily acting irrationally.

The findings are robust to a variety of plausible investment strategies and methodologies. ${ }^{2}$ For example, the result remains when we introduce short selling constraints or allow for hedging foreign exchange (FX) risk using forward contracts. We apply different statistical methodologies, including asymptotic tests, simulated small-sample distributions and no arbitrage Hansen-Jagannathan bounds. We evaluate the out-of-sample properties of theoretically optimal investment portfolios relative to a $100 \%$ domestic allocation portfolio for investment horizons up to three

1. This presumes the absence of market imperfections such as transaction costs, deviations from purchasing power parity, and inflation risk. See, amongst others, Adler and Dumas (1983) and Stulz (1984).

2. Some, but not all, are reported in this version of the paper. 
years. Consistent with the in-sample findings, out-of-sample results reveal that the Sharpe ratio of the theoretically optimal portfolio is typically below the Sharpe ratio of the $100 \%$ domestic portfolio. This indicates that benefits from international diversification are difficult to capture in practice.

The remainder of the paper is organized as follows. Section 2 describes the econometric methodology employed in the tests on the significance of the home bias. Section 3 describes the data. Section 4 reports the in-sample test results of allocations and the out-of-sample tests of investment performance. Finally, section 5 concludes the paper.

\section{Econometric Methodology}

We adopt the mean-variance framework as the premise for determining an international equity portfolio. From the view of investors in each G-5 country, we estimate the theoretically optimal, tangency portfolio based on in-sample data (from 1973 to 1994) and compare the tangency allocation weights to allocations associated with extreme home bias. Additionally we compare the out-of-sample (1995 to 1997) performance of the tangency portfolios to portfolios that exhibit a strong home bias.

We employ two different methods for estimation of the expected return vector, $E[R]$, and the variance-covariance matrix, $V C V$, used as inputs to the investors' mean-variance optimization; (1) a "Markowitz based" approach in which the expected returns and the variancecovariance matrix, $V C V$ parameters are estimated as the historical mean and $V C V$ matrices, and (2) a "Bayes-Stein shrinkage estimator" approach, which has been shown by Jorion $(1985,1986)$ to out perform the Markowitz based approach in out-of-sample investment performance tests.

In both the Markowitz and Bayes-Stein approaches the parameters, $E[R]$ and $V C V$, cannot be estimated precisely. ${ }^{3}$ Any optimization procedure passes the imprecision of the input parameters through to the outputs, tangency allocation weights, and hence provides that the tangency portfolio weights are also suffer from imprecision, see

3. Although precision is improved with Bayes-Stein when compared to Markowitz. 
Michaud (1998). ${ }^{4}$ This imprecision of the tangency weights is responsible for not being able to statistically distinguish these portfolio weights from those associated with extreme (100\%) home bias. We follow French and Poterba (1991) and consider equity for Group of Five (G-5) countries, and hence a $100 \%$ allocation of domestic equities is described by the $5 \times 1$ vector $\left[\begin{array}{lllll}1 & 0 & 0 & 0 & 0\end{array}\right]^{\prime}$ with $100 \%$ weighting in the home country (first entry) and zero weighting in the four foreign countries.

This inability to distinguish between the tangency vector and [1 00 $00]^{\prime}$ is couched in statistical terms as the failure to reject the null that the tangency allocation equals $\left[\begin{array}{lllll}1 & 0 & 0 & 0 & 0\end{array}\right]^{\prime}$. Loosely speaking, this insample finding can also be couched as accepting the notion that the truly optimal international portfolio allocation (whatever it is) is probably not statistically different than a $100 \%$ domestic allocation.

In addition to the above in-sample tests, we also conduct out-ofsample tests of investment performance of the tangency portfolios across three investment horizons. Based on views from (i) all five countries, and (ii) across one, two, and three year investment horizons, the $\left[\begin{array}{lllll}1 & 0 & 0 & 0 & 0\end{array}\right]^{\prime}$ allocation typically outperformed both the Markowitz and Bayes-Stein portfolios.

Unfortunately, tangency allocations associated with the Markowitz approach tend to perform poorly out-of-sample. Jorion $(1985,1986)$ demonstrates that an effective technique for improving out-of-sample performance of a Markowitz tangency portfolio is to modify the input parameters (i.e. $E[R]$ and $V C V$ ) so that they are effectively "shrunk" towards the mean and variance associated with the minimum variance portfolio $(M V P)$. These "shrinkage estimators" also commonly referred to as Bayes-Stein estimators, improve the out-of-sample performance vis-à-vis Markowitz. Intuitively, this improvement arises because the $M V P$ allocations depend only upon the sample $V C V$ matrix, and not upon the expected returns (which are notoriously difficult to estimate precisely). Hence, shrinking each asset's historical mean return toward the return of the $M V P$ portfolio improve precision associated with estimating the expected return of each asset. This improved estimation

4. The extensive literature on estimation error in portfolio choice includes Kalymon (1971), Frankfurter, Phillips, and Seagle (1971), Dickinson (1974), Burgess and Johnson (1976), Dhingra (1980), Jobson and Korkie (1980), Barry and Brown (1985), and Kandel, McCulloch, and Stambaugh (1995). 
of the expected returns results in improved out-of-sample performance. Specifically, the Bayes-Stein estimate of the expected return vector, $E\left[\boldsymbol{r}^{B S}\right]$, and the $V C V$ matrix, $\boldsymbol{\Sigma}^{B S}$, are computed as (using bold italics to indicate vectors and matrices):

$$
\begin{gathered}
E\left[\boldsymbol{r}^{B S}\right]=(1-\psi) \cdot \overline{\boldsymbol{r}}+\psi \cdot r_{M V P} \cdot \mathbf{1}, \\
\Sigma^{B S}=\Sigma \cdot\left(1+\frac{1}{T+\lambda}\right)+\frac{\lambda}{T(T+1+\lambda)} \cdot \frac{\mathbf{1} \cdot \mathbf{1}^{\prime}}{\mathbf{1}^{\prime} \Sigma^{-1} \mathbf{1}},
\end{gathered}
$$

where $\overline{\boldsymbol{r}}$ is the vector of historical mean returns, $r_{M V P}$ is the return associated with the $M V P, \boldsymbol{\Sigma}$ is the usual $V C V$ matrix (based upon historical returns), $\lambda$ is computed as:

$$
\lambda=\frac{(N+2)(T+1)}{\left(\overline{\boldsymbol{r}}-r_{M V P} \cdot \mathbf{1}\right) \cdot \Sigma^{-1} \cdot\left(\overline{\boldsymbol{r}}-r_{M V P} \cdot \mathbf{1}\right) \cdot(T-N-2)},
$$

and $\psi$ is the shrinkage factor, such that $\psi=\lambda(T+\lambda)$. In the BayesStein procedure, the historical mean return vector is shifted (or shrunk) toward the return associated with the minimum variance portfolio. Empirically, the degree of shift is substantial. That is, $\psi$ is typically in the range 0.88 to 0.95 .

Independent of the method of selecting the expected return vector and $V C V$ matrix (Bayes-Stein versus Markowitz), the tangency portfolio is the one that maximizes the Sharpe ratio. From the view of investors in each G-5 country, the weights associated with the tangency portfolio are found by solving a constrained mean-variance optimization problem similar to the unconstrained case in Markowitz (1959), and further analyzed in Roll (1977). Unlike these papers, we also investigate the case where investors cannot short sell. Therefore, when appropriate, the optimization incorporates inequality constraints related to short selling.

A discussion of the home bias promotes consideration of how investors may choose to hedge foreign exchange (FX) risk. This study allows for the hedging of FX risk across different risk management strategies, including the case in which there is no hedging of FX risk. 
With five countries under study, the no-hedging case involves five assets, whereas when hedging is allowed, four additional assets representing the returns on FX futures contracts are included as well, for a total of nine assets. Depending upon the type of FX hedging strategy allowed, additional constraints upon the optimization (in addition to any short selling constraints) are imposed.

Within this paper we focus on the no-hedging case. Additional results, available from the authors, demonstrate the robustness of the reported findings to various FX risk management strategies. In the interest of brevity, the ensuing discussion of econometric methodology assumes a no-hedging strategy, and hence includes only 5 assets, not 9 . For the case of five assets, the problem is one of constrained optimization, $\boldsymbol{w}_{T}=\arg$ max Sharpe ratio subject to:

$$
E[r]=\boldsymbol{w}^{\prime} \cdot E[\boldsymbol{r}], \sigma^{2}=\boldsymbol{w}^{\prime} \Sigma \boldsymbol{w}, \boldsymbol{i}^{\prime} \boldsymbol{w}=1, \boldsymbol{w} \geq \mathbf{0}
$$

where $\boldsymbol{w}_{T}$ is the $5 \times 1$ vector of portfolio weights (allocations) at the tangent; $\boldsymbol{w}$ is a $5 \times 1$ vector of weights, not necessarily at the tangent, covering the 5 equity weights, $E[\boldsymbol{r}]=E\left[r_{1} \ldots r_{5}\right]^{\prime}$ is the $5 \times 1$ vector of expected returns, $\Sigma$ is the $5 \times 5 V C V$ matrix of returns; $i$ is an $5 \times 1$ vector of ones; and $E[\cdot]$ is the mathematical expectation operator. Recall that the Sharpe ration is defined as $E\left[r^{e}\right] / \sigma$ where $r^{e}$ is the portfolio excess return. The last restriction is removed when we allow for the short selling of equity.

Let $\boldsymbol{w}_{\boldsymbol{o}}$ be the $\left[\begin{array}{lllll}1 & 0 & 0 & 0 & 0\end{array}\right]^{\prime}$ vector, and let $\boldsymbol{w}_{T}$ be the vector of equity weights associated with the tangent portfolio. The corresponding Wald test for is $H_{0}: \boldsymbol{w}_{T}=\boldsymbol{w}_{\boldsymbol{o}}, H_{1}: \boldsymbol{w}_{T} \neq \boldsymbol{w}_{\boldsymbol{o}}$

$$
W=\left[\boldsymbol{w}_{T}-\boldsymbol{w}_{o}\right]^{\prime} \Sigma_{w}^{-1} \cdot\left[\boldsymbol{w}_{T}-\boldsymbol{w}_{o}\right]
$$

where $\Sigma_{w}$ is the $5 \times 5 V C V$ matrix of the estimated portfolio weights, $\boldsymbol{w}_{T}{ }^{5}$ Due to the imposed constraint that the five equity weights sum to one, the rank of $\boldsymbol{\Sigma}_{w}$ is equal to the number of non-zero weighted equity markets minus one. Hence for estimations in which all five countries have non-zero weights, the rank of $\boldsymbol{\Sigma}_{w}$ is four. In this case, the

5. Empirical construction of $\boldsymbol{\Sigma}_{w}$ is described in the appendix. 
appropriate Wald test is constructed by selecting any four components of $\boldsymbol{w}_{\boldsymbol{o}}$ and $\boldsymbol{w}_{T}$ and the associated $4 \times 4 V C V$ matrix. In this case, the test statistic, $W$, is distributed $\chi_{4}^{2}$. For cases in which $\psi$ of the countries has a (binding) optimal investment weight of zero, the rank of $\boldsymbol{\Sigma}_{w}$ is reduced by $\psi$. In this case the test statistic is constructed in an analogous manner, and is distributed $\chi_{4-\psi}^{2}$

\section{Data}

The data employed cover the G-5 countries over the period July 1973 to December 1997, a 294 month period. For testing purposes, we split the data into an in-sample and out-of-sample period using July 1973 to December 1994 as the in-sample period, and January 1995 to December 1997 as the out-of-sample period. Data on local currency equity index returns with dividend reinvestment for the G-5 countries were obtained from Morgan Stanley Capital International (MSCI). Data on foreign exchange rates and eurocurrency rates were obtained from Data Resource International (DRI). The foreign exchange data consists of bid and ask quotes for both spot and one month forward contracts between the US dollar and the remaining G-5 countries. The eurocurrency quotes consist of bid and ask prices on 1 month deposits. ${ }^{6}$ The eurocurrency ask rates are used as risk-free rates for each G-5 country. All quotes from DRI are end of month from London's National Westminster Bank. Spot foreign exchange bid and ask cross-rates (i.e. not quoted vis-à-vis the dollar) were supplied by Telerate. The data set allows us to determine the tangent portfolio investment weights from the perspective of an investor in each G-5 country, not just from the perspective of a US investor.

\section{A. Construction of Returns}

Given monthly equity returns expressed in local currency terms, spot foreign exchange rates are employed to convert the returns into foreign currency terms. Excess returns are computed via subtracting the one month eurocurrency ask rate. For example, for a US investor investing

6. Eurocurrency rates for the yen are only available from February 1979 to December 1997, a 229 month period. 
$y$ dollars in the German equity market, the one month excess rate of return expressed in dollars is:

$$
r_{t+1}^{e}=\frac{\left\{\frac{y}{S_{t}^{D M}} \cdot\left(1+r_{t+1}^{D M}\right) \cdot S_{t+1}^{D M}\right\}}{y}-1-r_{f, t+1}^{U S}
$$

where $S_{t}^{D M}$ is the spot foreign exchange rate expressed in dollars per Deutsche mark at time $t, r_{t}^{D M}$ is the rate of return of German equities expressed in Deutsche mark terms for the period ending at time $t+1$, and $r_{f, t+1}^{U S}$ is the 1 month eurocurrency ask rate for US dollars deposited from time $t$ to time $t+1$. Analogously, a non-US investor investing in a non-US market would employ the spot cross-rate market.

In order to remove much of the foreign exchange risk associated with foreign equity investment, investors may elect to take hedge positions in foreign currency via foreign exchange forward contracts. Consider a US investor investing in the German equity market and taking a short forward position in order to hedge the FX risk. The rate of return associated with the forward hedge is expressed as:

$$
r_{t+1}^{H}=\frac{F_{t, t+1}^{D M}-S_{t+1}^{D M}}{S_{t}^{D M}},
$$

where $r_{t+1}^{H}$ is the return due to hedging via forward contracts from time $t$ to time $t+1$, and $F_{t, t+1}^{D M}$ is the forward rate contracted at time $t$ for exchanging Deutsche marks for dollars at time $t+1$. When an investor chooses to hedge a proportion, $\theta$, of the principal invested, the total return including the hedge is computed as $r_{t+1}^{e}+\theta \cdot{ }_{t+1}^{H}$.

\section{B. Descriptive Statistics}

Annualized historical mean and volatility of returns expressed in local currency are reported for the in-sample period (1973/07 - 1994/12) in table 1, panel A. In local currency terms the UK shows the highest 
average return (17.26\%) and highest volatility (24.01\%). Japan shows the lowest average return (10.15\%) and Germany shows the lowest volatility (18.04\%). Table 1, Panel B reports the foreign exchange spot returns from the view of an investor in each G-5 country. The yen (pound) appreciated (depreciated) against all other G-5 currencies over the period. The franc, mark and dollar were mixed against the other currencies. As demonstrated by panels A and B collectively, appreciation of the yen rewarded foreign investment in the Japanese equity market, while depreciation of the pound punished the UK equity market. Table 2 reports annualized excess returns, volatilities, and Sharpe ratios for $100 \%$ equity investment in each G-5 country, from the view of investors in each G-5 country. In four of the five country views, Japan (France) has the highest (lowest) Sharpe ratio.

Table 3 reports in-sample return correlations. Panel A is based on equity returns expressed in local terms, and spot foreign exchange returns expressed in dollar terms. The local market equity returns are positively correlated with other locally measured equity returns, ranging from a low of 0.2939 between Japan and Germany, to a high of 0.5765 between the US and the UK. Japan shows the lowest overall correlation of local equity returns with other local equity returns. The spot foreign exchange returns are sensitive to the country from which they are viewed. We have chosen to report them from the perspective of a US investor going long the foreign currency. Japan also shows the lowest overall correlation of spot foreign exchange returns with other spot foreign exchange returns.

Foreign exchange returns appear uncorrelated with returns of the local equity market. The mean correlation between a country's foreign exchange return and its local equity market return is 0.0257 from the perspective of U.S. investors. Panel B reports correlations from unhedged equity investment in dollar terms. As expected, given the evidence in panel A, Japan has the lowest overall correlations. The highest off-diagonal entry is associated with dollar returns between France and Germany (0.6026) while the lowest off-diagonal entry is associated with dollar returns between the US and Japan (0.2517).

Table 4 compares the expected return vectors from the view of each country using both the Markowitz and Bayes-Stein approaches. The associated shrinkage weights are reported as well. For example, from panel B, the shrinkage factor from the US view is 0.8939, the Markowitz 


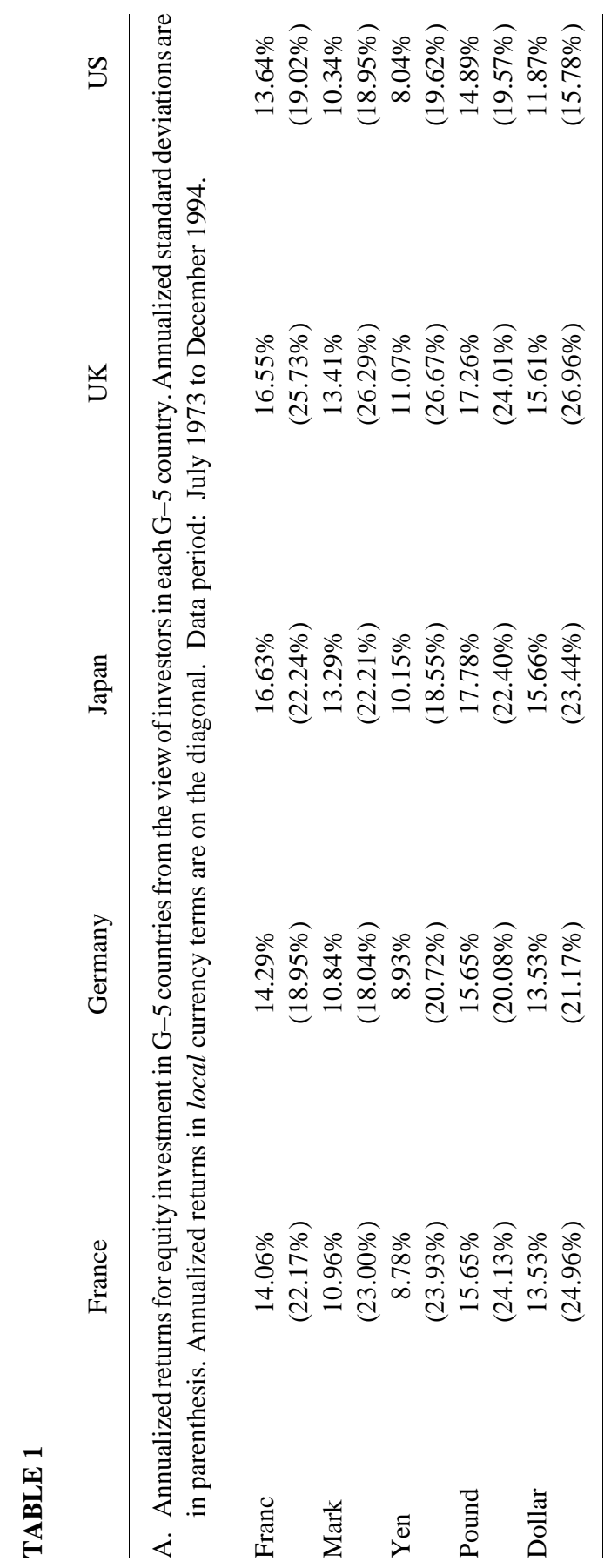




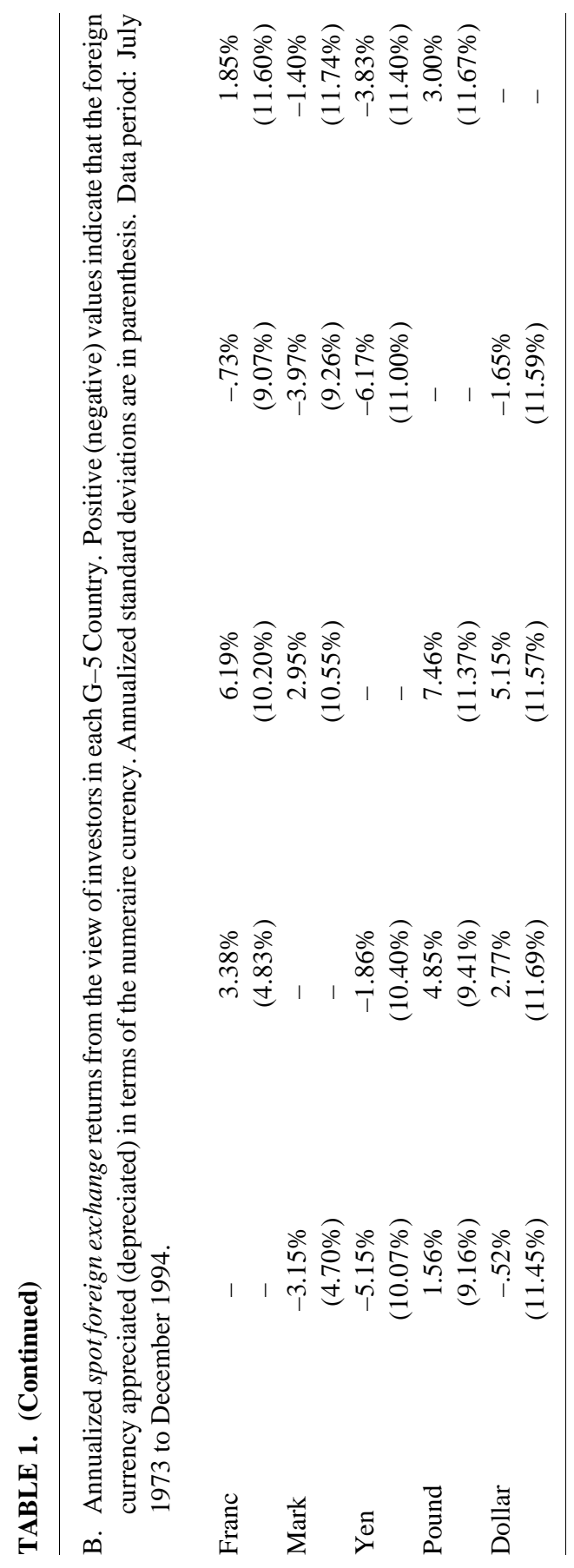




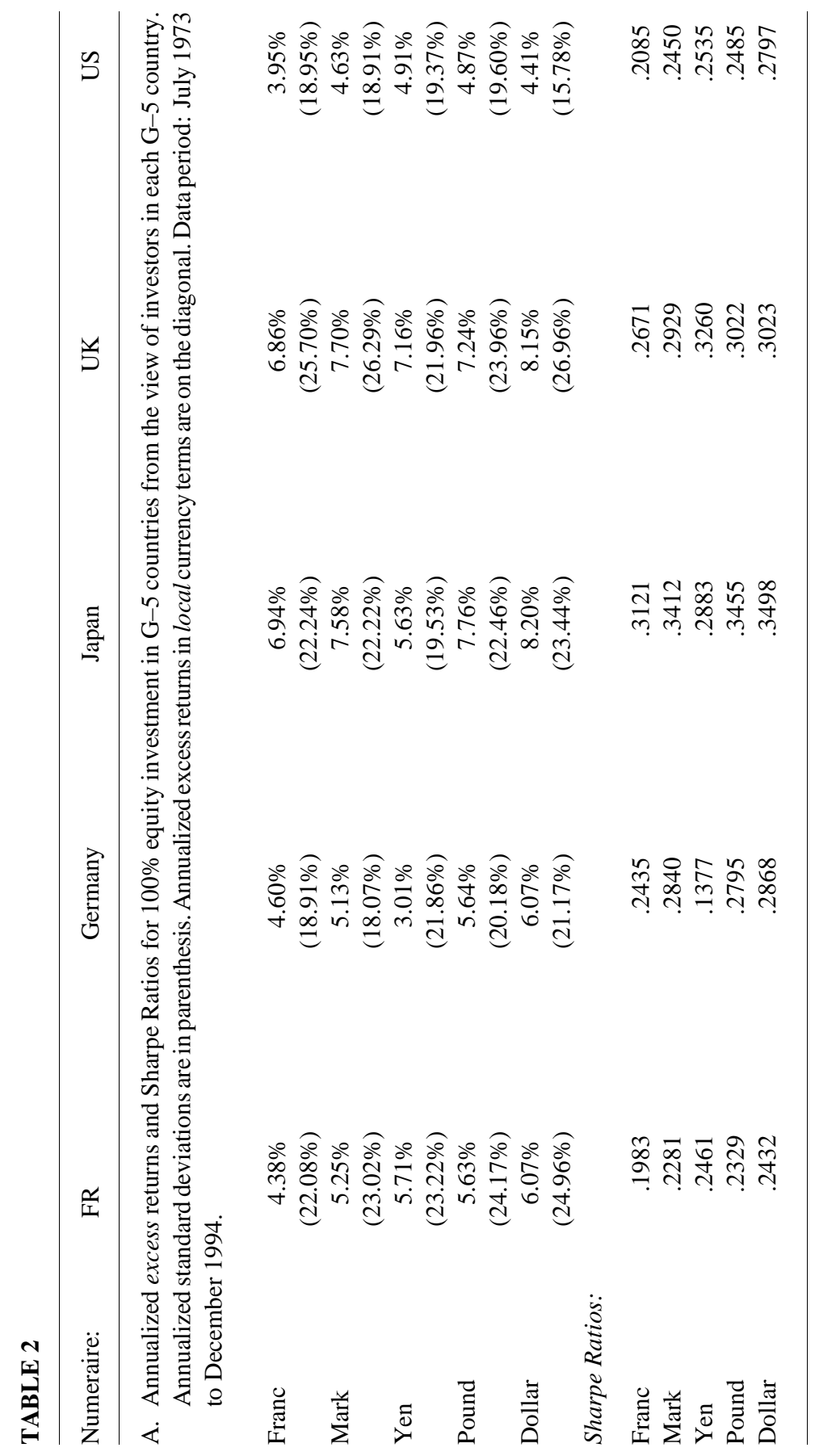




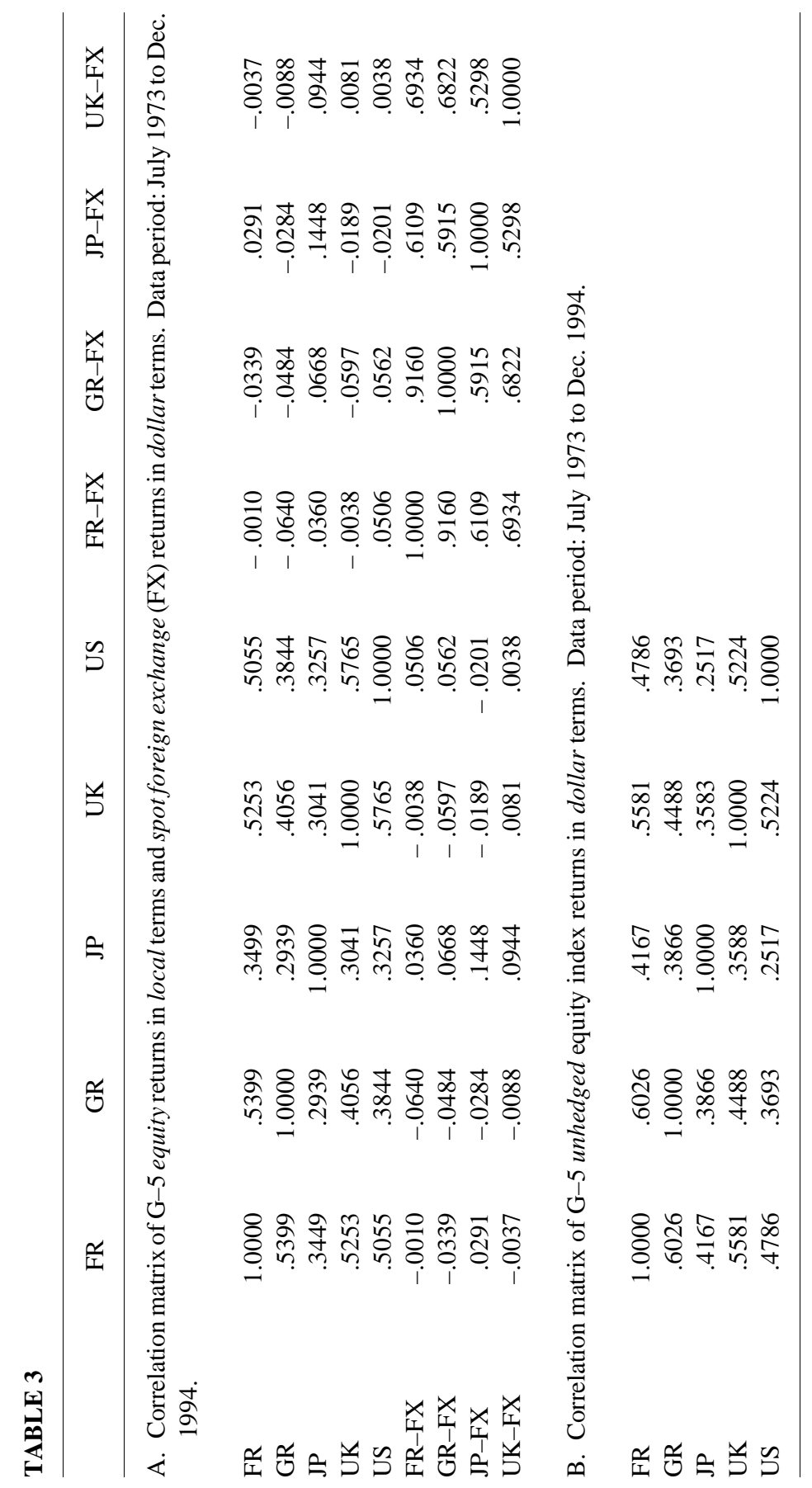




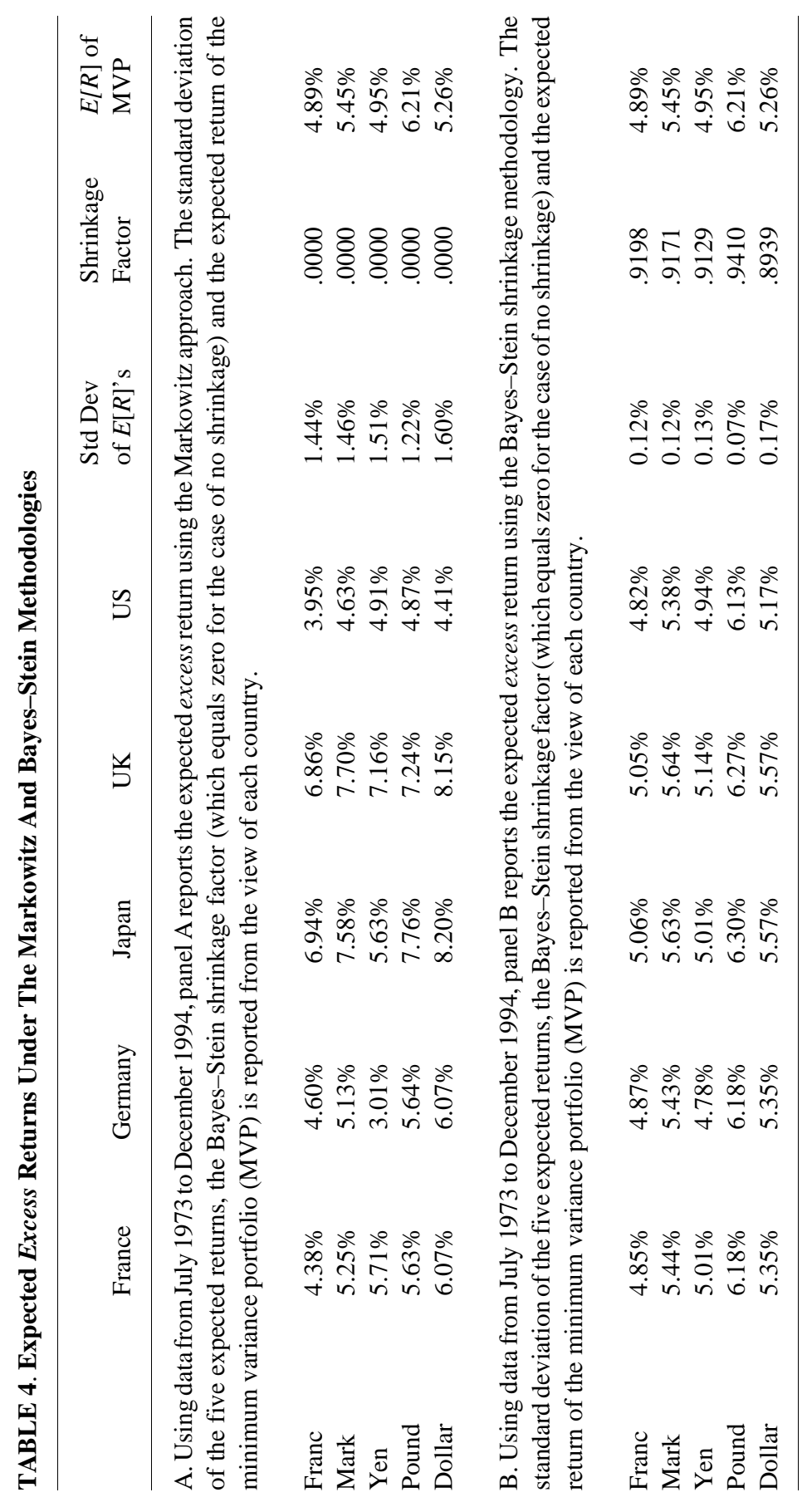


based expected excess return of Japan is $8.20 \%$, and the expected return of the MVP is $5.26 \%$. The resulting expected excess return of Japan under Bayes-Stein is 5.57\%. Effectively, the Bayes-Stein expected returns are determined by heavily shifting the Markowitz expected returns toward the expected return of the MVP. A much more modest degree of shrinkage is associated with the variancecovariance matrices.

\section{Results}

Our framework allows for hedging FX risk through taking positions in futures contracts. We have determined that the results presented below are effectively insensitive to a wide range of FX hedge strategies. Given the robustness of the findings to FX hedging, we limit the current discussion to investment strategies that do not involve futures contracts. ${ }^{7}$

\section{A. In-Sample Allocation Tests}

In order to address the home bias issue from a diverse perspective (not just from the perspective of a US investor), each strategy is analyzed separately from the view of an investor in each G-5 country. Panel A of table 5 reports the tangency allocations in the Bayes-Stein case, in the no short selling scenario. Notice that from some perspectives, the tangency allocation to France and/or the U.K. is zero. This stems from a combination of relatively low excess returns in the French and UK equity markets and relatively large off-diagonal covariance entries associated with France and the UK.

The maximum domestic equity investment weight across the five countries is associated with the US. Mean-variance optimization under Bayes-Stein prescribes that Americans should invest $60.31 \%$ of their assets in the U.S. equity market, substantially below the actual investment allocation of $92.9 \%$ reported by French and Poterba (1991). However, the standard error associated with this portfolio estimate is

7. A detailed analysis of in-sample allocations and subsequent out-of-sample performance stemming from strategies that allow for FX hedging is available from the authors upon request. These "with hedging" results are supportive of the "without hedging" results upon which we focus. 


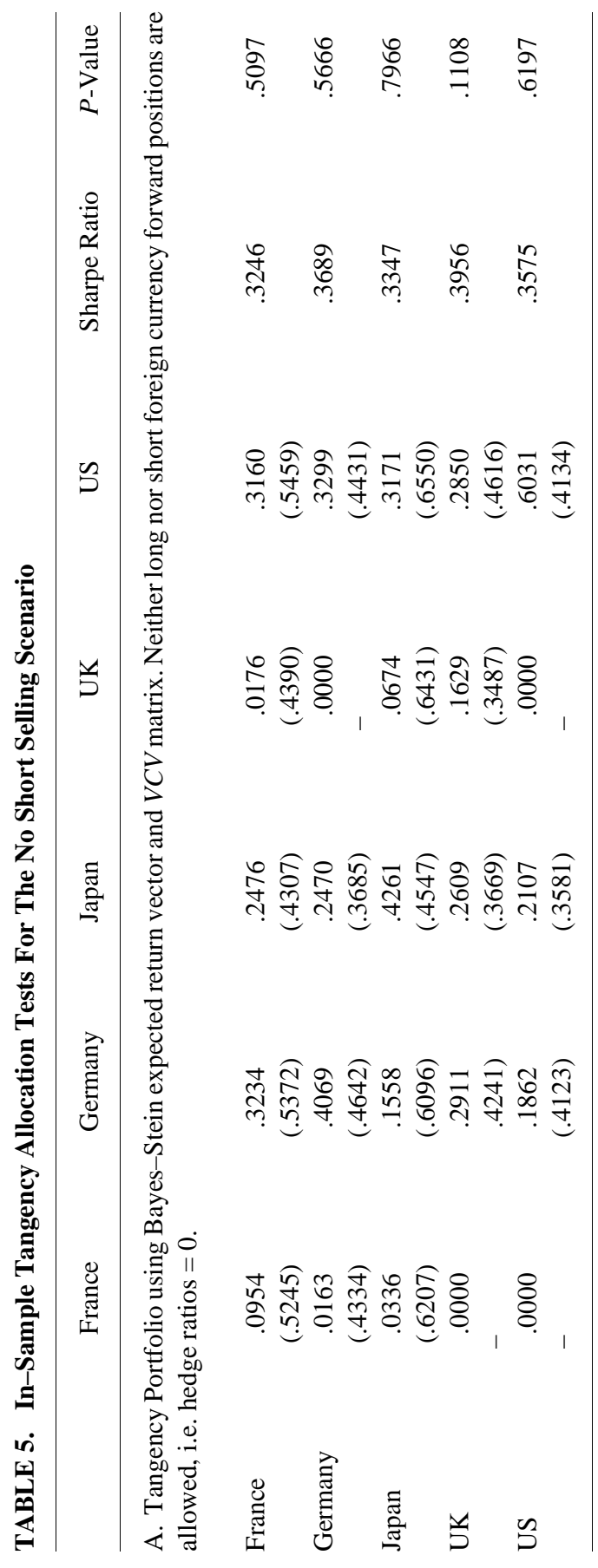




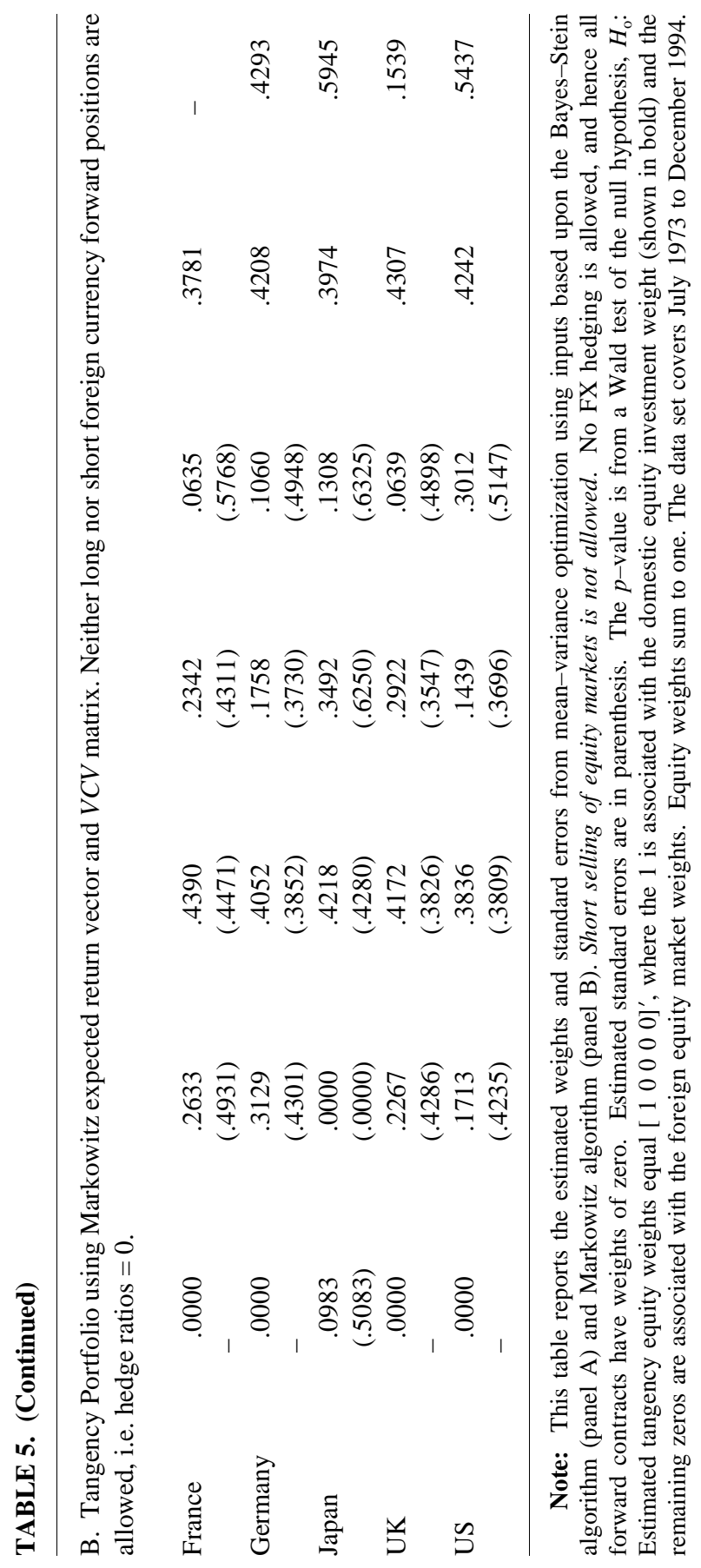


0.4134. Therefore, the tangency weight estimate of $60.31 \%$ is only 0.79 standard errors away from the actual investment weight of $92.9 \%$. One could therefore conclude that the observed home bias for American investors is not a statistical anomaly.

French and Poterba estimate the actual domestic equity investment of UK investors to be $92.0 \%$. Given the tangency estimate of $16.29 \%$ with standard error of 0.3487 , the estimate is 2.17 standard errors from the actual portfolio weight. This $t$-test argument rejects the null hypothesis that tangency weights equal the actual weights. In this case, unlike the American view, one could conclude that from the UK view home bias is a statistical anomaly. Similar calculations for France, Germany and Japan indicate that the tangency weights are 1.52, 0.83, and 1.17 standard errors away from the actual weights, respectively. Overall, these initial test results appear mixed.

The above $t$-tests are tests of a single weight, specifically the domestic equity allocation. However, investors may allocate funds across multiple foreign equity markets. For example, French and Poterba (1991) estimate that in December 1989 a US investor invested $0.5 \%, 0.5 \%, 3.1 \%$, and $1.1 \%$ of assets in France, Germany, Japan, and the UK, respectively. Given the broad choice of international equity markets available to investors, a joint test is appropriate.

In principle, we could test whether the tangent weights are equal to actual equity weights held by the representative investor. That is, we could test the null hypothesis $H_{0}: \boldsymbol{w}_{\text {Tang }}=\boldsymbol{w}_{\text {Actual, }}$, against the alternative $H_{1}: \boldsymbol{w}_{\text {Tang }} \neq \boldsymbol{w}_{\text {Actual }}$. Unfortunately, the actual portfolio weights reported by French and Poterba (1991), such as:

$$
\boldsymbol{w}_{\text {Actual }}^{\text {US }}=\left[\begin{array}{lllll}
.948 & .005 & .005 & .031 & .011
\end{array}\right]^{\prime}
$$

from the US perspective, are subject to substantial measurement error, since they are "crude estimates of the equity portfolio allocation [p. 222]".

Lacking accurate estimates of actual portfolio holdings, we substitute the extreme vector of $\left[\begin{array}{lllll}1 & 0 & 0 & 0 & 0\end{array}\right]^{\prime}$ indicating $100 \%$ domestic allocation, for the actual allocation vector (whatever it may be). With this substitution, we test whether the estimated tangent weights are significantly different than $\left[\begin{array}{lllll}1 & 0 & 0 & 0 & 0\end{array}\right]^{\prime}$, the most extreme form of home 
bias. That is, we apply the null hypothesis, $H_{0:} \boldsymbol{w}_{\text {Tang }}=\left[\begin{array}{lllll}1 & 0 & 0 & 0 & 0\end{array}\right]^{\prime}$, against the (two-sided) alternative, $H_{1:} \boldsymbol{w}_{\text {Tang }} \neq\left[\begin{array}{lllll}1 & 0 & 0 & 0 & 0\end{array}\right]^{\prime}$. We employ the previously described Wald statistic (2.1) for testing purposes.

Of course, imposing the extreme $100 \%$ home bias vector of [1 00 $00]^{\prime}$ into the null hypothesis of the tests, rather than an actual allocation vector such as [.948.005.005.031 .011]', serves to bias the test methodology towards increased power, which ultimately makes the inability to reject the null hypothesis more difficult to achieve.

Table 5, panel A reports $p$-values resulting from the Wald test (2.1). The smallest $p$-value is 0.1108 , associated with investment from a UK perspective. Therefore, from the view of investors in each G-5 country, the Bayes-Stein tangency weights are not significantly different than [1 $\left.\begin{array}{lllll}0 & 0 & 0 & 0\end{array}\right]^{\prime}$. Table 5, panel B reports parallel results under the Markowitz methodology. In this case, the lowest $p$-value is 0.1539 , again indicating that the null hypothesis is not rejected. Taking into account the finding of panels $\mathrm{A}$ and $\mathrm{B}$, the findings are consistent with the belief that investors with a $100 \%$ domestic market allocation are not allocating their assets in a manner that is significantly different than theoretically predicted portfolio allocations.

Table 6 relaxes the no-short sales constraint imposed previously in table 5. Table 6, panel A reports on tangency allocations when short selling is allowed in the Bayes-Stein case. In this scenario, German, UK and US investors take short positions in the French and/or UK markets, although the degree of shorting is modest (the most extreme hedging occurs when a US investor allocates $6.47 \%$ of their wealth to a short position in French equities). Given the modest degree of shorting, it is not surprising that the $p$-values of table 6, panel A closely resemble those of table 5, panel A. In the case of table 6, the minimum $p$-value is 0.1956 , indicating a failure to reject the null hypothesis from the view of investors in each G-5 country. Table 6, panel B reports results under the Markowitz approach and when short selling of equity is allowed. In this scenario, the lowest $p$-value is 0.2523 , again indicating that the null hypothesis is not rejected.

Overall, the infrequent rejection of the null necessitates a concern for low inherent power of the tests. Small sample simulations, available from the authors, indicate that the infrequent rejection of the null hypothesis is not likely due to deviations from the assumed $\chi_{4}^{2}$ asymptotic distribution. Additionally, the use of an extreme vector, $\left[\begin{array}{lllll}1 & 0 & 0 & 0 & 0\end{array}\right]^{\prime}$, in 


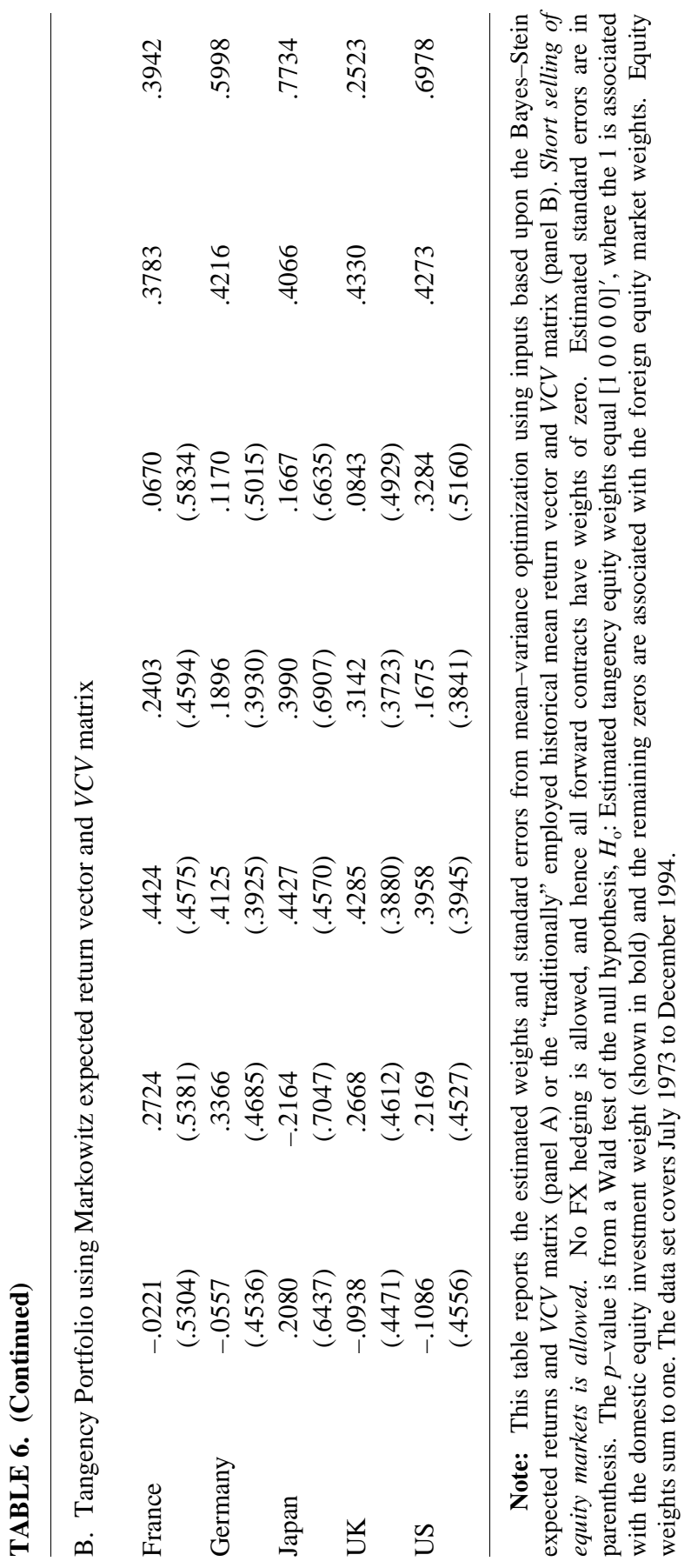


the null (rather than the actual allocation vector, whatever it may be) serves to increase the power of the test.

Taking into account tables 5 and 6 , these in-sample findings demonstrate that the tangency allocation is not significantly different than $\left[\begin{array}{lllll}1 & 0 & 0 & 0 & 0\end{array}\right]^{\prime}$. This finding appears robust across (1) the availability of short sale opportunities, (2) the ability to hedge FX risk, and (3) the methodology used to estimate the expected return vector and $V C V$ matrix. In summary, we conclude that a $100 \%$ domestic allocation is not significantly different than an allocation based upon either the BayesStein or Markowitz methodology. That is, the tangency portfolio is insignificantly different than $\left[\begin{array}{lllll}1 & 0 & 0 & 0 & 0\end{array}\right]^{\prime}$.

\section{B. Out-of-Sample Tests of Investment Performance}

Using allocation weights estimated over the in-sample period July 1973 to December 1994, we investigate how returns associated with a $100 \%$ domestic allocation compare to (1) the Bayes-Stein portfolio returns and (2) the Markowitz portfolio returns in the subsequent period. We refer to the period July 1973 to December 1994 as the in-sample period, and investigate three out-of-sample periods covering the subsequent 12, 24, and 36 month periods. Essentially, we wish to determine if the tangency portfolio allocation in December 1994, which outperformed the domestic portfolio in the 1973/07 to 1994/12 period, can again outperform a $100 \%$ domestic allocation in three out-of-sample periods beginning January 1995. From the view of each G-5 country, we compute a signed-rank test under the null hypothesis that the monthly returns associated with the domestic market are equal to the monthly returns associated with the tangency portfolio. We also compute Sharpe ratios for each country view, and subsequently compute the overall mean (across all G-5 countries) of the Sharpe ratio measures.

Table 7 reports on the out-of-sample performance of the Bayes-Stein portfolio for the no shorting case. ${ }^{8}$ Panel A reports performance in the 12 month period January 1995 to December 1995. The returns of the Bayes-Stein portfolio have a correlation that ranges from 0.4659 (French view) to 0.7601 (US view) with the returns of the $100 \%$ domestic allocation portfolio. The ranked sum statistic's p-value is never below 0.05 which indicates that neither portfolio out-performed the other in this

8. The "with shorting" case, not reported here, produces essentially the same findings. 


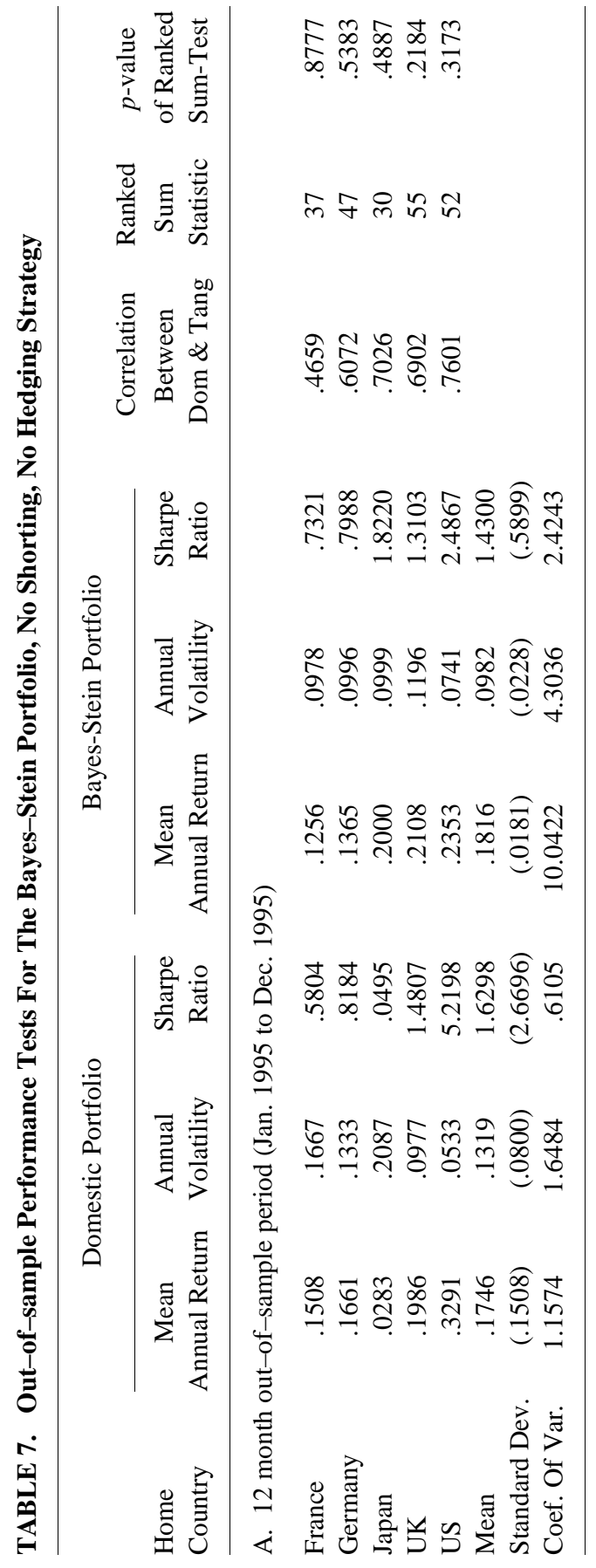




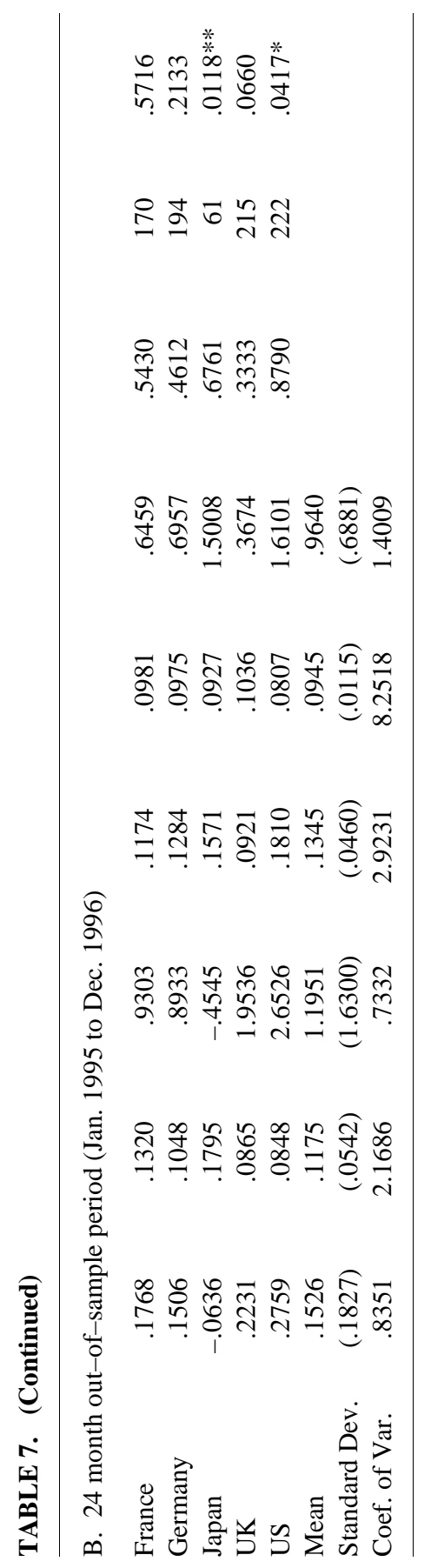




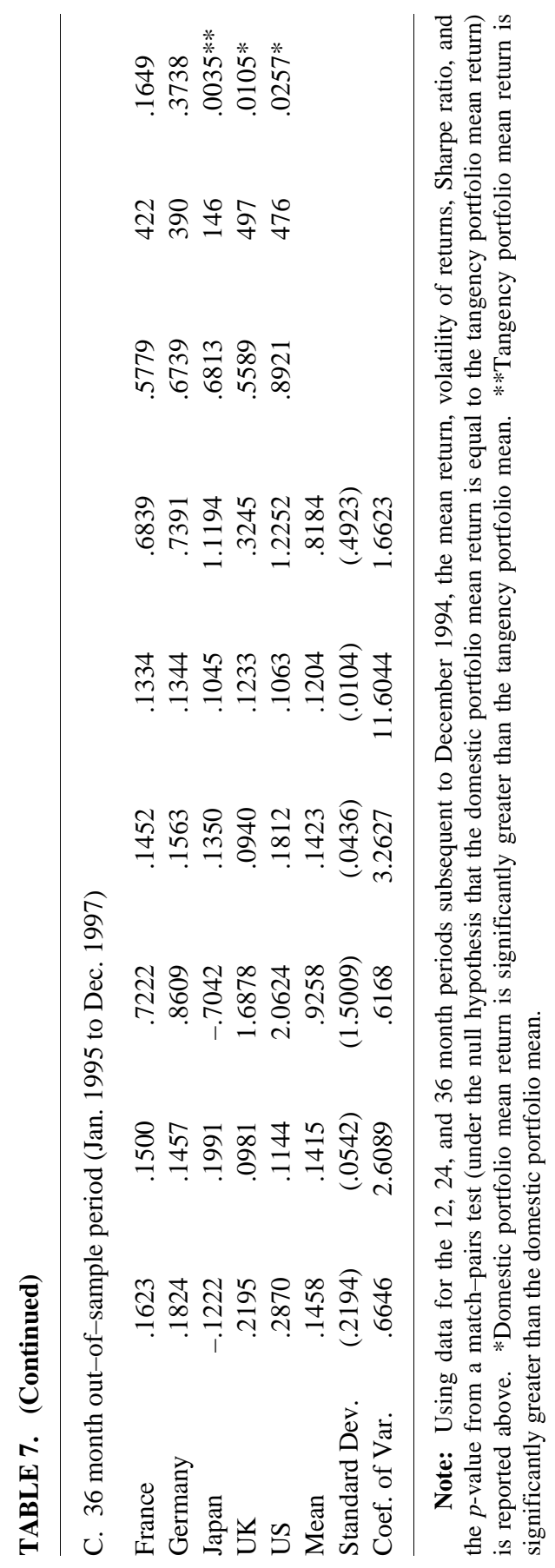


12-month period. Although close, the advantage seems to reside with the $100 \%$ domestic portfolio as witnessed by a higher mean Sharpe ratio (across the five different views) of 1.6298 vs. 1.4300 for the BayesStein portfolios.

Table 7, panel B reports performance in the 24-month period January 1995 to December 1996. The ranked sum statistic's $p$-value is below the critical value of 0.05 in 2 of the 5 cases, which leaves a mixed impression. Specifically, from the Japanese (UK) view, the Bayes-Stein (100\% domestic) portfolio outperformed in a significant manner. The overall mean Sharpe ratio associated with the $100 \%$ domestic portfolio of 1.1951, is larger than the mean Sharpe ratio associated with the Bayes-Stein portfolio of 0.9640 . On average, the $100 \%$ domestic allocation appears to have outperformed the Bayes-Stein portfolio in this 24-month period.

Table 7, panel C reports performance in the 36-month period January 1995 to December 1997. The ranked sum statistic's $p$-value indicates that the Bayes-Stein portfolio outperformed the $100 \%$ domestic portfolio from the view of a Japanese investor. However, the $100 \%$ domestic portfolio outperformed the Bayes-Stein portfolio from the view of investors in both the UK and the US. In summary, the mean Sharpe ratio associated with the $100 \%$ domestic portfolio of 0.9258 , is larger than the mean Sharpe ratio associated with the Bayes-Stein portfolio of 0.8184 . Again, on average the $100 \%$ domestic allocation appears to have outperformed the Bayes-Stein portfolio.

Table 8 reports on the out-of-sample performance of the Markowitz tangency portfolio. Panel A reports performance in the 12-month period January 1995 to December 1995 . The returns of the Markowitz portfolio have a correlation that ranges from 0.4027 (German view) to 0.7934 (UK view) with the returns of the $100 \%$ domestic allocation portfolio. The ranked sum statistic's p-value is never below 0.05 , which indicates that neither portfolio out-performed the other in this 12-month period. Again, as in Bayes-Stein performance evaluations of table 7, the performance advantage resides with the $100 \%$ domestic portfolio as witnessed by a higher mean Sharpe ratio (across the five different views) of 1.6298 , versus 0.5996 for the Markowitz tangency

The values of the mean Sharpe ratios associated with the $100 \%$ domestic allocation portfolio, the Bayes-Stein portfolio, and the Markowitz portfolio are $1.6298,1.4300$, and 0.5996 respectively. 


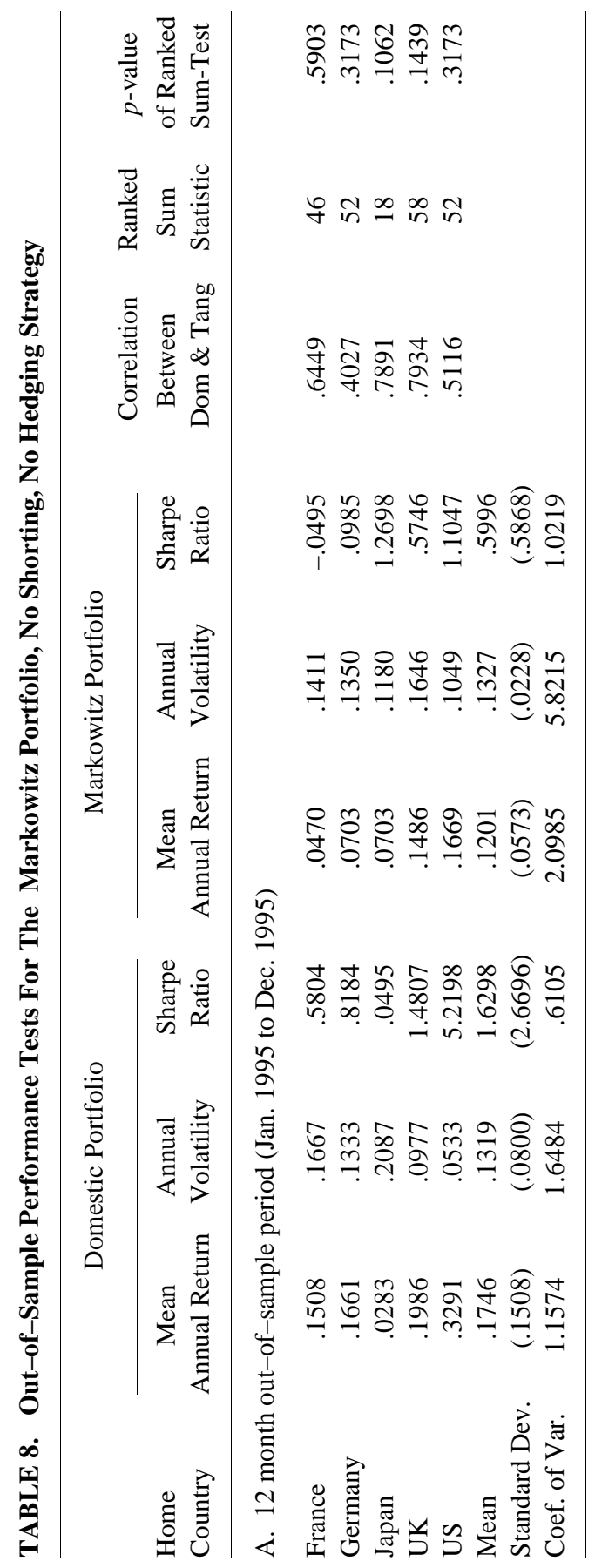




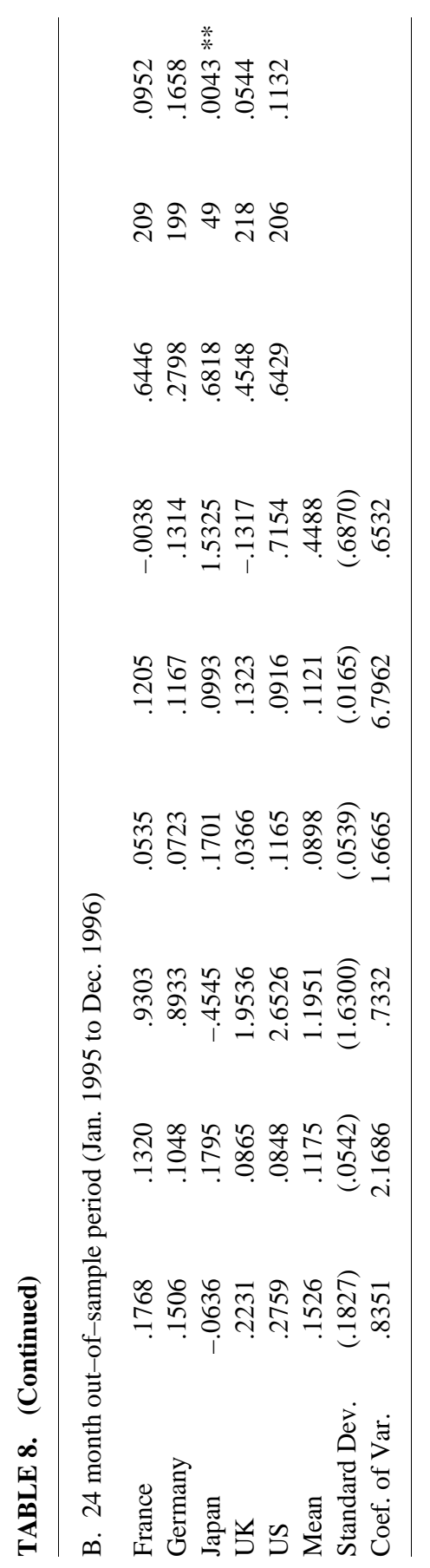




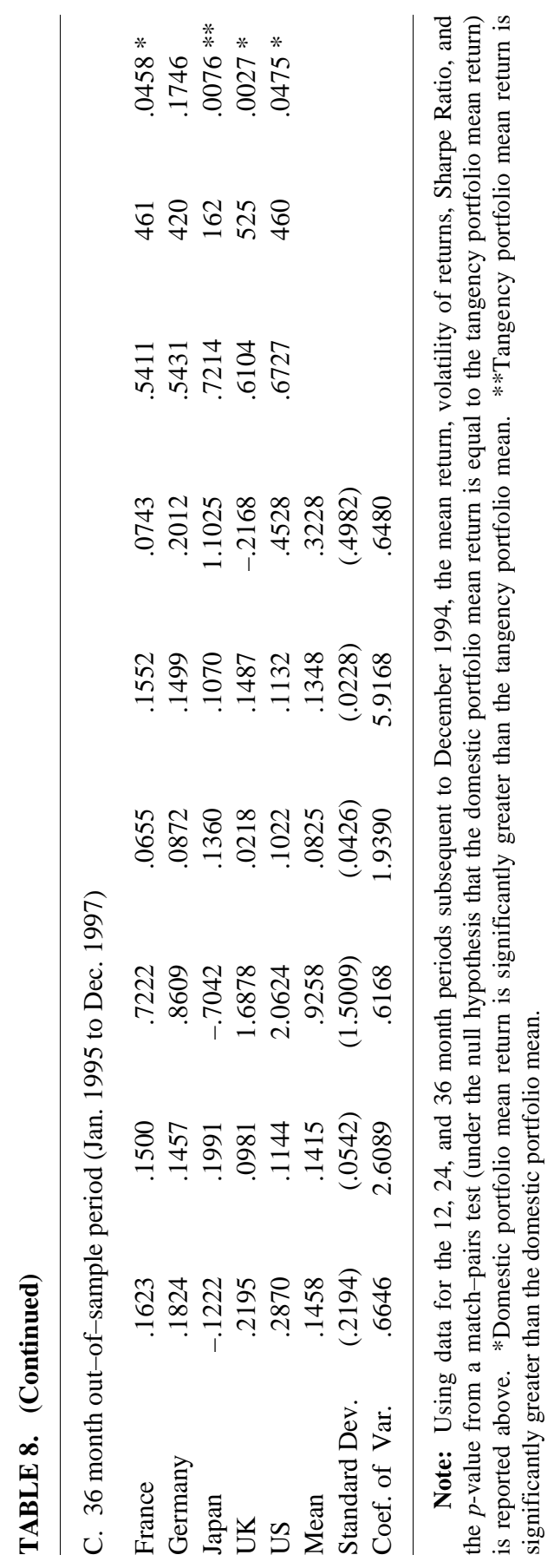


Consistent with previous findings of Jorion $(1985,1986)$ the out-ofsample performance of the Bayes-Stein portfolio is superior to that of the Markowitz portfolio. On the whole, the $100 \%$ domestic allocation portfolio, $\left[\begin{array}{lllll}1 & 0 & 0 & 0 & 0\end{array}\right]^{\prime}$, is the best performer. This provides substantial evidence that although there are theoretical advantages to international diversification, in actuality it can be difficult to capture such advantages.

Table 8, panel B reports performance in the 24-month period January 1995 to December 1996. The ranked sum statistic's $p$-value is below the critical 0.05 value in 1 of the 5 cases. Specifically, from the Japanese view, the Markowitz portfolio outperformed the $100 \%$ domestic portfolio. Yet the mean Sharpe ratio associated with the $100 \%$ domestic portfolio of 1.1951, is still larger than the mean Sharpe ratio associated with the Markowitz portfolio of 0.4488 . On average, the $100 \%$ domestic allocation appears to have outperformed the Markowitz portfolio in this 2-year period. Consistent with the findings in panel A of tables 7 and 8, the highest mean Sharpe ratio is associated with the $100 \%$ domestic allocation portfolio, followed by the Bayes-Stein portfolio, and then the Markowitz portfolio (respective values of 1.1951, 0.9640 , and 0.4488 ). We conclude that, in this period of study, any gains to international diversification appear difficult to capture in practice.

Table 8, panel C reports performance in the 36-month period January 1995 to December 1997. The ranked sum statistic's $p$-value is below the critical 0.05 value in 4 of the 5 cases. In 3 of the 4 cases, the $100 \%$ domestic portfolio outperformed the Markowitz portfolio (from the French, UK and US views) while from the Japanese view, the Markowitz portfolio outperformed the $100 \%$ domestic portfolio. Overall, the mean Sharpe ratio associated with the $100 \%$ domestic portfolio of 0.9258, which is larger than the mean Sharpe ratio associated with the Markowitz portfolio of 0.3228 . Once again, on average, the $100 \%$ domestic allocation appears to have outperformed the Markowitz portfolio. When taking into account the findings reported in table 7 , panel C, the highest mean Sharpe ratio is associated with the 100\% domestic allocation portfolio, followed by the Bayes-Stein portfolio, and then the Markowitz portfolio (respective values of 0.9258, 0.8184, and 0.3228).

To summarize across Tables 7 and 8 , the out-of-sample statistical evidence indicates that the theoretical benefits to international 
diversification are difficult to achieve in practice. ${ }^{9}$ For both the BayesStein and Markowitz methodologies, we find that a $100 \%$ domestic allocation typically performs as well or better than the tangency portfolio.

A common thread of explanation across the in-sample and out-ofsample results is the role that the $V C V$ matrix associated with the data generating mechanism (DGM) of returns plays. The large variance of the DGM makes estimation of the expected returns imprecise. This causes distinct portfolio allocations to be statistically indistinguishable, as demonstrated repeatedly in the in-sample findings. Further, the large variance of the DGM produces out-of-sample performances that can vary across allocation strategies in non-anticipated ways.

\section{Conclusion}

This paper investigates whether investors' domestic equity holdings, which may at first appear to be excessive, constitute an anomaly in the statistical sense. The in-sample allocation tests demonstrate that portfolio allocations representing extreme home are not significantly different than the portfolio allocations associated with the theoretically optimal tangency portfolios. The result is driven primarily by the substantial imprecision associated with estimating the expected return vector and $V C V$ matrix. These findings hold for both a Markowitz and a Bayes-Stein approach to estimation of the $E[R]$ and $V C V$ parameters. The results are effectively insensitive to imposing or relaxing short selling and FX hedging constraints.

The out-of-sample performance tests provide evidence that theoretical international diversification benefits are particularly difficult to capture in practice. We find that a $100 \%$ domestic allocation typically performs as well or better than the estimated tangency portfolios. The explanation for the poor out-of-sample investment performance is, like the in-sample tests, highly dependent upon the large variance associated

9. When out-of-sample performance is measured across various strategies that allow for the hedging of FX risk through futures contracts, the results parallel the findings in Tables 7 and 8 . That is, a 100\% domestic allocation portfolio performs better out of sample compared to a "with hedging" tangency portfolio. Results are available from the authors upon request. 
with the data generating mechanism. Intuitively, the standard errors associated with estimation of the parameters of the data generating mechanism are simply too large for an investor to accurately forecast what the future returns will be.

This study addresses the role of estimation uncertainty in explaining anomalies. We explore whether estimation risk calls into question whether the home bias is an "irrational" bias. In particular, we address mean-variance portfolio choices in two cases. First, in the Markowitz case, we presume that investors know the return parameters, the expected returns and the variance covariance matrix of returns. Nonetheless, estimation risk arises in this setting as we estimate the investors' tangency portfolio. Second, in the Bayes-Stein case, we assume that investors do not know the return parameters, instead they chose tangent portfolios using Bayesian updating based on the observed returns. ${ }^{10}$ The reported results might suggest that other anomalies, such as size effects and post-earnings announcement drift, could be explained by either Bayesian investors' behavior or investors' learning. We leave this possibility for future work.

\section{Appendix}

This appendix describes the numerical procedure for determining the standard errors associated with the portfolio weights of the tangent portfolio. The procedure allows for FX hedging via long and short futures contracts used for risk-management purposes. We estimate the tangent portfolios numerically. ${ }^{11}$

For the case in which hedging of FX risk is allowed, there are nine assets in question (five equity indices and four FX futures contracts). We define the 9 dimensional vector of tangent portfolio weights, $\boldsymbol{w}_{T}=f(\boldsymbol{\theta})$, as a function of the 54 dimensional vector $\boldsymbol{\theta} \equiv\left[E\left[\boldsymbol{r}^{\mathrm{e}}\right]^{\prime} \operatorname{vech}(\Sigma)^{\prime}\right]^{\prime}{ }^{12}$ Hence, $\boldsymbol{f}(\boldsymbol{\theta})$ is a function with 54 inputs ( $9 E[R]$ 's, 54 unique VCV entries) and 9 outputs (tangency weights).

A first order Taylor series expansion of $\boldsymbol{f}(\boldsymbol{\theta})$ around $\hat{\theta}$ yields:

10. This second case is similar to Pastor (2000) who presumes that investors observed portfolio choices are the result of Bayesian analysis and infers the loading factor, on the investors' prior that explains the home bias.

11. We employ optimization routines within Matlab and confirm their high precision against known closed form solutions when available.

12. The vech operator transforms an $(n \times n)$ matrix into an $([n(n+1) / 2] \times 1)$ vector by vertically stacking the lower triangular entries. 


$$
f(\theta) \cong f(\hat{\theta})+\nabla f(\hat{\theta}) \cdot(\theta-\hat{\theta})
$$

where $\hat{\theta}$ is the sample estimate of $\boldsymbol{\theta}$. Taking the variance of the Taylor expansion gives :

$$
\Sigma_{w} \cong \nabla f(\hat{\theta}) \cdot \Sigma_{\hat{\theta}} \cdot \nabla f(\hat{\theta})^{\prime}
$$

where $\nabla f(\hat{\theta})$ is of dimension $9 \times 54, \Sigma_{\hat{\theta}}$ is $54 \times 54$, and $\Sigma_{w}$ is $9 \times 9$. The gradient $\nabla \boldsymbol{f}$ is computed numerically in Matlab using a forward differencing algorithm.

The square root of the diagonal entries of (A), appropriately scaled by the number of periods, provides an estimate of the standard errors of the estimated tangent weights. ${ }^{13}$ Due to the definition of $\boldsymbol{\theta}$, these standard errors take into account estimation error in both the expected return vector and the $V C V$ matrix. Estimation of $\boldsymbol{\theta}$ is straightforward and allows for the computation of the $54 \times 54$ $V C V$ matrix $\Sigma_{\hat{\theta}}$. For each period $t=1, \ldots, T$, form $y_{t}$ defined as:

$$
y_{t}=\left[\begin{array}{c}
r_{t}^{e 1} \\
\vdots \\
r_{t}^{9} \\
\left(r_{t}^{e 1}-\bar{r}_{t}^{e 1}\right)^{2} \\
\left(r_{t}^{e 1}-\bar{r}_{t}^{e 1}\right)\left(r_{t}^{e 2}-\bar{r}_{t}^{e 2}\right) \\
\left(r_{t}^{e 1}-\bar{r}_{t}^{e 1}\right)\left(r_{t}^{e 3}-\bar{r}_{t}^{e 3}\right) \\
\vdots \\
\left(r_{t}^{8}-\bar{r}_{t}^{8}\right)^{2} \\
\left(r_{t}^{8}-\bar{r}_{t}^{8}\right)\left(r_{t}^{9}-\bar{r}_{t}^{9}\right) \\
\left(r_{t}^{9}-\bar{r}_{t}^{9}\right)^{2}
\end{array}\right],
$$

where $r_{t}^{e j}\left(\bar{r}^{e j}\right)$ is the excess return (mean excess return) of the $j^{\text {th }}$ equity index in period $t, j=1, \ldots . .5$; and $r_{t}^{k}\left(\bar{r}^{k}\right)$ is the hedge return (mean hedge return) of the

13. The methodology is also known as the delta method. 
$k^{\text {th }}$ forward contract in period $t, k=6, \ldots 9 .{ }^{14}$ Let $\tilde{\theta} \equiv\left[\begin{array}{llll}y_{1} & y_{2} & \ldots & y_{T}\end{array}\right]$. With these defined, we then define $\theta=\left(\tilde{\theta} \cdot i_{t}\right) / T$ and construct $\Sigma_{\hat{\theta}}$ by computing the 54 $\times 54 V C V$ matrix of $\tilde{\theta}$. The upper left $9 \times 9$ sub-matrix of $\Sigma_{\hat{\theta}}$ is the $V C V$ matrix of the excess returns, while the lower right $45 \times 45$ sub-matrix of $\Sigma_{\hat{\theta}}$ is the $V C V$ matrix of the second moments of the excess returns. The remaining entries measure the covariance between the first and second moments of the excess returns. Collectively, $\Sigma_{\hat{\theta}}$ measures how accurately the first and second moments of the excess returns are estimated in $\hat{\theta}$. With $\Sigma_{\hat{\theta}}$ estimated, the 9 $\times 9$ matrix $\Sigma_{\mathrm{w}}(\mathrm{A})$, which measures the precision with which the tangency weights are estimated, can be used to test joint hypotheses concerning the home bias.

For the case of "no-hedging" (in which there is only 5 assets, not 9) the analogous algorithm for estimating the $5 \times 1$ vector of the tangency portfolio weights, $\boldsymbol{f}(\boldsymbol{\theta})$, and their associated degree of estimation precision $\Sigma_{\mathrm{w}}($ a $5 \times 5$ matrix) is employed. In this case $\boldsymbol{w}_{T}$ equals $\boldsymbol{f}(\boldsymbol{\theta})$ and $\Sigma_{\mathrm{w}, 5}$ equals $\Sigma_{\mathrm{w}}$, and hence there is no need to extract a $5 \times 1$ sub-vector from a $9 \times 1$ vector, nor is there a need to extract a $5 \times 5$ sub-matrix from a $9 \times 9$ matrix. The vectors and matrices required for hypothesis testing, $\boldsymbol{w}_{T}$ and $\Sigma_{\mathrm{w}}$, are obtained directly.

\section{References}

Adler, M., and Dumas, B. 1983. International portfolio choice and corporate finance: A synthesis. The Journal of Finance 38 (June): 925-984.

Bailey, W., and Stulz, R. M. 1990. Benefits of international diversification: The case of pacific basin stock markets. Journal of Portfolio Management 16 (Summer): 57-61.

Barry, C. B., and Brown, S. J. 1985. Differential information and security market equilibrium. Journal of Financial and Quantitative Analysis 20 (December): 407-422.

Bekaert, G., and Urias, M. S. 1996. Diversification, integration and emerging market closed-end funds. The Journal of Finance 51 (July): 835-869.

Burgess, R. C., and Johnson, K. H. 1976. The effects of sampling fluctuations on the required inputs of security analysis. Journal of Financial and Quantitative Analysis 11 (December): 847-854.

De Santis, G. 1995. Volatility bounds for statistical discount factors: Tests and

14. Hereafter we refer to the $9 \times 1$ return vector as the excess return vector even though the last four entries, associated with foreign exchange forward positions, are not expressed in excess of the risk free rate. 
implications from international financial markets. Working paper. Los Angeles: University of Southern California.

De Santis, G., and Gerard, B. 1997. International asset pricing and portfolio diversification with time-varying risk. The Journal of Finance 52 (December): 1881-1912.

Dhingra, H. L. 1980. Effects of estimation risk on efficient portfolios: A Monte Carlo simulation study. Journal of Business, Finance and Accounting 7 (Spring): 277-295.

Dickinson, J.P. 1974. The reliability of estimation procedures in portfolio analysis. Journal of Financial and Quantitative Analysis 9 (June): 447-462.

Errunza, V.; Hogan, K.; and Hung, M.-W. 1999. Can the gains from international diversification be achieved without trading abroad? The Journal of Finance 54 (December): 2075-2107.

Eun, C. S., and Resnick, B. G. 1988. Exchange rate uncertainty, forward contracts and international portfolio selection. The Journal of Finance 43 (March): 197-215.

Frankfurter, G. M.; Phillips, H. E; and Seagle, J. P. 1971. Portfolio selection: The effects of uncertain means, variances, and covariances. Journal of Financial and Quantitative Analysis 6 (December): 1251-1262.

French, K. R., and Poterba, J. M. 1991. Investor diversification and international equity markets. American Economic Review, Papers and Proceedings 81: 222-226.

Hansen, L. P., and Jagannathan, R. 1991. Implications of security market data for models of dynamic economies. Journal of Political Economy 99 (April): 225-262.

Jobson, J. D., and Korkie, B. M. 1980. Estimation for Markowitz efficient portfolios. Journal of the American Statistical Association 75 (September): 544-554.

Jorion, P. 1985. International portfolio diversification with estimation risk. Journal of Business 58 (July): 259-278.

Jorion, P. 1986. Bayes-Stein estimation for portfolio analysis. Journal of Financial and Quantitative Analysis 21 (September): 279-292.

Kalymon, B. A. 1971. Estimation risk in the portfolio selection model. Journal of Financial and Quantitative Analysis 6 (January): 559-582.

Kandel, S.; McCulloch, R.; and Stambaugh, R. F. 1995. Bayesian inference and portfolio efficiency. The Review of Financial Studies 8 (Spring): 1-53.

Levy, H. 1980. The capital asset pricing model, inflation, and the investment horizon: The Israeli experience. The Journal of Financial and Quantitative Analysis 15 (September): 561-593.

Lewis, K. K. 1999. Trying to explain home bias in equities and consumption. Journal of Economic Literature 37 (June): 571-608.

Markowitz, H. M. 1959. Portfolio selection. Journal of Finance 7 (February): $77-$ 91. 
Michaud, R. O. 1998. Efficient Asset Management: A Practical Guide to Stock Portfolio Optimization and Asset Allocation. Boston, MA: Harvard Business School Press.

Pastor, L. 2000. Portfolio selection and asset pricing models. Journal of Finance 55 (February): 179-223.

Roll, R. 1977. A critique of the asset pricing theory's tests. Part I: On past and potential testability of the theory. Journal of Financial Economics 4 (March): 129-176.

Solnik, B. H. 1974. Why not diversify internationally rather than domestically? Financial Analysts Journal 30 (July): 48-54.

Stulz, R. M. 1984. Pricing capital assets in an international setting: An introduction. Journal of International Business Studies 15 (Winter): 55-73. 